\title{
ANALISIS KAPASITAS LATERAL PADA FONDASI TIANG TUNGGAL DAN TIANG KELOMPOK PADA TANAH PASIR
}

\author{
Morrischo $^{1}$, Hendy Wijaya ${ }^{2}$, dan Amelia Yuwono ${ }^{3}$ \\ ${ }^{1}$ Program Studi Sarjana Teknik Sipil, Universitas Tarumanagara, Jl. Letjen S. Parman No.1 Jakarta \\ Morrischo.325160121@stu.untar.ac.id \\ ${ }^{2}$ Program Studi Sarjana Teknik Sipil, Universitas Tarumanagara, Jl. Letjen S. Parman No.1 Jakarta \\ rm.hendy@yahoo.com \\ ${ }^{3}$ Program Studi Sarjana Teknik Sipil, Universitas Tarumanagara, Jl. Letjen S. Parman No.1 Jakarta \\ yuwonoamelia@gmail.com
}

Masuk: 06-07-2020, revisi: 08-07-2020, diterima untuk diterbitkan: 04-08-2020

\begin{abstract}
The foundation is part of an engineering system that forwards the burden supported by the foundation and its own weight into the soil and rocks beneath. In this journal, an analysis of the lateral capacity of single piles and group piles is carried out on sandy soil. To be able to analyze a single pile and group piles on sandy soil in elastic conditions can be done by non-linear static analysis or pushover analysis. Pushover analysis is an analysis procedure to determine the collapse of a building by providing a certain static load pattern in the lateral direction whose magnitude will be increased gradually until the structure reaches a certain displacement target or reaches a certain collapse pattern. From the results of pushover analysis on a pile, a curve that connects the base shear and roof displacement is called a capacity curve. From the capacity curve, it can be seen the behavior of a pile from elastic to plastic conditions to failure. With the obtained capacity curve, we can see the level of performance of a pile based on the capacity spectrum method based on ATC-40 regulations and Pushover Analysis of Underground Structures.
\end{abstract}

Keywords: single and group pile foundations; pushover analysis; lateral capacity

\begin{abstract}
ABSTRAK
Fondasi ialah bagian dari suatu sistem rekayasa yang meneruskan beban yang ditopang oleh fondasi dan beratnya sendiri kedalam tanah dan batuan yang terletak dibawahnya. Pada jurnal ini, dilakukan analisis kapasitas lateral tiang tunggal dan tiang kelompok pada tanah pasir. Untuk dapat menganalisis tiang pancang tunggal dan tiang kelompok pada tanah pasir dalam kondisi elastic dapat dilakukan dengan metode analisis statik non linier atau analisis pushover. Analisis pushover adalah prosedur analisis untuk mengetahui keruntuhan suatu bangunan dengan memberikan suatu pola beban statik tertentu dalam arah lateral yang besarnya akan ditingkatkan secara bertahap sampai struktur tersebut mencapai target displacement tertentu atau mencapai pola keruntuhan tertentu. Dari hasil analisis pushover terhadap suatu tiang dihasilkan kurva yang menghubungkan antara base shear dan roof displacement atau disebut kurva kapasitas. Dari kurva kapasitas tersebut dapat dilihat perilaku suatu tiang dari kondisi elastis sampai plastis hingga mengalami kegagalan. Dengan adanya kurva kapasitas yang diperoleh, kita dapat melihat tingkat kinerja suatu tiang berdasarkan metode spektrum kapasitas berdasarkan peraturan ATC-40 dan Pushover Analysis of Underground Structures.
\end{abstract}

Kata kunci: fondasi tiang tunggal dan kelompok; analisis pushover; kapasitas lateral.

\section{PENDAHULUAN}

Dalam suatu pekerjaan komstruksi pasti terdapat struktur pondasi, pondasi menjadi salah satu faktor pemting yang membuat suatu bangunan dapat kokoh berdiri. Fondasi memiliki fungsi untuk menahan beban aksial dan lateral yang diteruskan kebagian tanah pendukung bangunan tersebut.

Untuk bangunan yang sederhana gaya lateral yang diterima sangat kecil sehingga dapat di abaikan, tetapi pada bangunan khusus seperti jembatan atau bangunan pencakar langit tidak dapat di abaikan. Beban lateral dapat diakibatkan karena adanya gempa, angin, dan gelombang air laut, oleh karena itu analisis dan desain terhadap beban lateral harus di perhitungkan agar tiang pancang itu sendiri dapat berfungsi dengan baik. 
Di berlakukannya SNI 1726 : 2019 yang menggantikan SNI 1726 : 2012 sehingga ada daerah tertentu yang mengalami kenaikan percepatan gempa sehingga gaya gempa yang di terima fondasi meningkat. Oleh karena itu perlu dilakukan analisis terhadap tiang tunggal dan tiang kelompok dengan berbagai percepatan gempa pada kondisi elastik, salah satunya adalah dengan analisis statik non linier atau analisis pushover. Untuk dapat menganalisis terjadinya beban lateral maka dapat digunakan program berbasis geoteknik.

analisis terhadap tiang tunggal dan tiang kelompok dengan berbagai percepatan gempa pada kondisi elastik, salah satunya adalah dengan analisis statik non linier atau analisis pushover. Untuk dapat menganalisis terjadinya beban lateral maka dapat digunakan program berbasis geoteknik.

Pada penelitian ini, pemodelan tiang pancang terhadap beban lateral dilakukan dengan software berbasis geoteknik dengan konfigurasi tiang pancang tunggal kotak dimensi $25 \times 25 \mathrm{~cm}, 30 \times 30 \mathrm{~cm}, 35 \times 35 \mathrm{~cm}, 40 \times 40 \mathrm{~cm}$, $50 \times 50 \mathrm{~cm}$ dan berbentuk spun yang berdimensi $300 \mathrm{~mm}, 400 \mathrm{~mm}, 500 \mathrm{~mm}, 800 \mathrm{~mm}, 1000 \mathrm{~mm}$. Sedangkan untuk konfigurasi tiang kelompok yang digunakan adalah 7 tiang, 8 tiang, 10 tiang, dan 11 tiang. Beban gempa yang digunakan dalam perencanaan adalah beban gempa berdasarkan SNI 1726:2019 untuk wilayah Jakarta dengan jenis tanah lunak dan kedalaman tiang yang dipakai adalah $11 \mathrm{~m}$ (cut off level $-3.5 \mathrm{~m}$ ) dan panjang tiang $7.5 \mathrm{~m}$. Kemudian untuk pemodelan tanah pada penelitian ini menggunakan tanah pasir dengan sudut geser $10^{\circ}$ dan parameter tanah yang digunakan merupakan parameter buatan yang tidak diambil dari proyek sesungguhnya.

Tujuan dari penelitian ini adalah untuk mengetahui besarnya gaya lateral maksimum yang dapat diterima tiang tuanggal dan tiang kelompok pada kondisi elastic, mengetahui besarnya displacement yang terjadi pada tiang tunggal dan tiang kelompok yang diberikan gaya lateral maksimum pada kondisi elastik, dan untuk mengetahui tingkat kinerja struktur pada tiang tunggal dan tiang kelompok yang direncanakan dengan SNI 1726 : 2019 melalui analisis pushover menurut peraturan ATC-40 dan Pushover Analysis of Underground Structures.

\section{METODE PENELITIAN}

Pada analisis ini, data tanah yang akan digunakan dan dianalisis mengikuti SNI 1726:2019. Data tanah yang digunakan adalah tanah pasir dengan kepadatan lepas. Respon Spektra yang digunakan adalah untuk wilayah Jakarta dengan Kategori SE (Tanah Lunak)

Sebelum dilakukan pengolahan data, dilakukan studi literatur untuk memahami dasar-dasar teori yang perlu diperhatikan dan rumus-rumus yang akan digunakan untuk analisis. Setelah dilakukan studi literatur, data-data yang telah dikumpulkan dimasukan ke dalam program dengan memasukkan parameter-parameter yang telah ditentukan seperti beban lateral, jenis tanah, dan dimensi tiang. Kemudian diteruskan dengan melakukan analisis perhitungan kapasitas tiang fondasi berdasarkan titik kinerja struktur metode ATC-40.

Dalam metode $A T C-40$, tingkat kinerja struktur ditentukan dengan menggunakan metode spektrum kapasitas (capacity-spectrum), yaitu dengan memplotkan demand respons spektrum dan kurva kapasitas dalam satu format antara spektral percepatan dan spektral perpindahan atau disebut sebagai format Acceleration-Displacement Response Spectra $(A D R S)$.

Kurva kapasitas (capacity-curve) diperoleh dari analisis pushover, yaitu analisis statik nonlinier dengan memberikan beban lateral statik tertentu pada struktur yang kemudian ditingkatkan secara bertahap hingga struktur mencapai suatu batas tertentu atau mengalami kegagalan struktur. Respons struktur terhadap beban lateral tersebut dicatat dan dibuat kurva hubungan antara gaya geser dasar, "V" dan perpindahan pada atap, " $\Delta_{\text {atap }}$. Kurva tersebut-lah yang disebut sebagai kurva kapasitas.

Kurva kapasitas menggambarkan kekuatan struktur yang besarnya sangat tergantung dari kemampuan deformasi masing-masing elemen struktur. Untuk mengubah kurva kapasitas ke dalam format ADRS atau menjadi spektrum kapasitas diperlukan pemahaman tentang hubungan faktor partisipasi modal, modal koefisien massa, dan perpindahan bangunan. Untuk mengubah kurva kapasitas ke dalam format ADRS digunakan persamaanpersamaan 1 - 4

$$
\begin{aligned}
S_{a} & =\frac{V / W}{\alpha_{1}} \\
S_{d} & =\frac{\Delta_{\text {roof }}}{P F_{1} \phi_{\text {roof. } 1}}
\end{aligned}
$$

Demand spektrum diperoleh dengan mengubah respons spektrum yang biasanya dinyatakan dalam spektra percepatan "Sa" dan periode "T" menjadi format ADRS (Sa, Sd) dengan menggunakan persamaan 3 sehingga diperoleh kurva demand spectrum.

$$
S_{d}=\frac{T^{2}}{4 \pi^{2}} S_{a} \cdot(g)
$$


Selanjutnya, grafik spektrum kapasitas dan spektrum demand digambarkan dalam satu grafik ADRS. Dalam grafik tersebut akan mendapatkan nilai $\alpha y$, Dy, $\alpha$ i, Dpi, selanjutnya dihitung nilai $\beta o$ dan $\beta$ eq untuk mencari nilai SRA dan SRV yang akan digunakan untuk mendapatkan nilai redaman yang tereduksi (Sa x SRA/SRV), kemudian hasil nilai redaman tereduksi tersebut digambarkan dalam satu grafik ADRS bersamaan dengan grafik spectrum kapasitas dan spectrum demand sebelum tereduksi. Titik perpotongan antara kurva kapasitas dengan kurva redaman yang tereduksi disebut sebagai titik kineja atau performance point.

$$
\begin{aligned}
\beta_{o} & =\frac{63.7(\alpha y D p i-D y \alpha p i)}{\alpha p i D p i} \\
\beta_{e q} & =\beta_{o}+0,05 \\
\mathrm{SRA} & =\frac{3.21-0.68 \ln \left(\beta_{e q}\right)}{2.12} \\
\mathrm{SRV} & =\frac{2.31-0.41 \ln \left(\beta_{e q}\right)}{1.65}
\end{aligned}
$$

dengan $\mathrm{Sa}=\operatorname{spektra}$ percepatan $(\mathrm{g}), \mathrm{V}=$ gaya geser dasar $(\mathrm{kN}), \mathrm{W}=$ berat tiang $(\mathrm{kN}), \mathrm{Sd}=$ spektra perpindahan (m), $\Delta_{\text {roof }}=$ perpindahan atap $(\mathrm{m}), \mathrm{PF}=$ faktor partisipasi modal pada mode pertama, $\mathrm{T}=$ periode getar fundamental (detik), $\mathrm{g}=$ percepatan gravitasi $\left(9,81 \mathrm{~m} / \mathrm{s}^{2}\right)$, $\alpha \mathrm{y}=$ percepatan pada titik leleh struktur $(\mathrm{g}), \mathrm{dy}=$ perpindahan pada titik leleh struktur (m), api = percepatan pada titik akhir struktur $(\mathrm{g})$, dpi = perpindahan pada titik akhir struktur (m) Alur atau tahapan dari penelitian ini tertera dalam bentuk diagram pada Gambar 1.

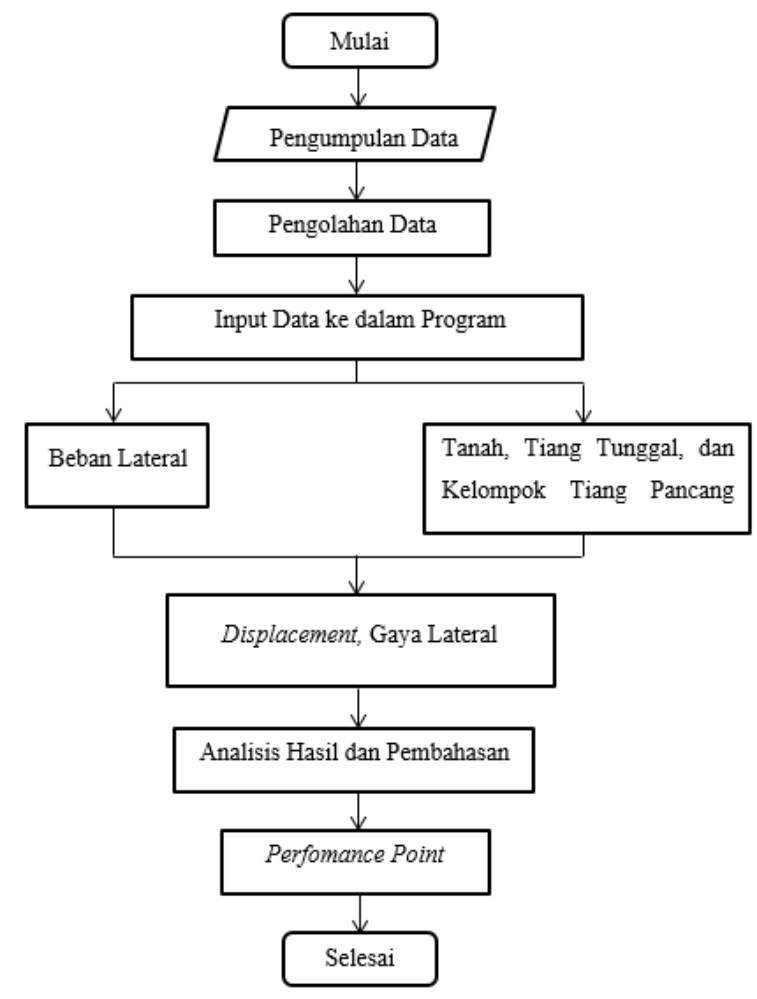

Gambar 1. Diagram alur penelitian

\section{HASIL DAN PEMBAHASAN}

\section{Hasil analisis tiang pancang tunggal dan tiang kelompok}

Setelah dilakukan analisis pushover sesuai dengan SNI 1726:2019 yang mengacu pada metode ATC-40, pada tiang pancang tunggal dan tiang kelompok pada kondisi Free Head dan Fixed Head di berbagai dimensi. Hasil yang didapat berupa kurva kapasitas, yang kemudian diubah menjadi spektrum kapasitas. Dari analisis tersebut didapat performance point dan pile drift ratio yang akan digunakan untuk menentukan tingkat kinerja tiang pancang tunggal tersebut seperti pada tabel 1-4 
Tabel 1. Hasil analisis tiang kotak elastik

\begin{tabular}{|c|c|c|c|c|c|c|c|}
\hline Tipe & & $\begin{array}{l}\text { Ukuran } \\
(\mathrm{mm})\end{array}$ & $\begin{array}{l}\text { Depth } \\
\text { (m) }\end{array}$ & $\begin{array}{c}\text { Performance } \\
\text { Point }\end{array}$ & $\begin{array}{c}\text { Pile Drift } \\
\text { Ratio } \\
(\%)\end{array}$ & Kategori & Kesimpulan \\
\hline Kotak Elastik & $\begin{array}{l}\text { Free } \\
\text { head }\end{array}$ & 250 & 7,5 & 0,04 & 0,54 & 0,01 & $\begin{array}{l}\text { Immediate } \\
\text { Occupancy }\end{array}$ \\
\hline Kotak Elastik & $\begin{array}{l}\text { Free } \\
\text { head }\end{array}$ & 250 & 7,5 & 0,04 & 0,54 & $<1,5 \%$ & $\begin{array}{c}\text { Life safe-damage } \\
\text { state }\end{array}$ \\
\hline Kotak Elastik & $\begin{array}{l}\text { Free } \\
\text { head }\end{array}$ & 300 & 7,5 & 0,04 & 0,54 & 0,01 & $\begin{array}{l}\text { Immediate } \\
\text { Occupancy }\end{array}$ \\
\hline Kotak Elastik & $\begin{array}{l}\text { Free } \\
\text { head }\end{array}$ & 300 & 7,5 & 0,04 & 0,54 & $<1,5 \%$ & $\begin{array}{c}\text { Life safe-damage } \\
\text { state }\end{array}$ \\
\hline Kotak Elastik & $\begin{array}{l}\text { Free } \\
\text { head }\end{array}$ & 350 & 7,5 & 0,045 & 0,6 & 0,01 & $\begin{array}{l}\text { Immediate } \\
\text { Occupancy }\end{array}$ \\
\hline Kotak Elastik & $\begin{array}{l}\text { Free } \\
\text { head }\end{array}$ & 350 & 7,5 & 0,045 & 0,6 & $<1,5 \%$ & $\begin{array}{c}\text { Life safe-damage } \\
\text { state }\end{array}$ \\
\hline Kotak Elastik & $\begin{array}{l}\text { Free } \\
\text { head }\end{array}$ & 400 & 7,5 & 0,05 & 0,67 & 0,01 & $\begin{array}{l}\text { Immediate } \\
\text { Occupancy }\end{array}$ \\
\hline Kotak Elastik & $\begin{array}{l}\text { Free } \\
\text { head }\end{array}$ & 400 & 7,5 & 0,05 & 0,67 & $<1,5 \%$ & $\begin{array}{c}\text { Life safe-damage } \\
\text { state }\end{array}$ \\
\hline Kotak Elastik & $\begin{array}{l}\text { Free } \\
\text { head }\end{array}$ & 500 & 7,5 & 0,05 & 0,67 & 0,01 & $\begin{array}{l}\text { Immediate } \\
\text { Occupancy }\end{array}$ \\
\hline Kotak Elastik & $\begin{array}{l}\text { Free } \\
\text { head }\end{array}$ & 500 & 7,5 & 0,05 & 0,67 & $<1,5 \%$ & $\begin{array}{c}\text { Life safe-damage } \\
\text { state }\end{array}$ \\
\hline Kotak Elastik & $\begin{array}{l}\text { Fixed } \\
\text { head }\end{array}$ & 250 & 7,5 & 0,115 & 1,54 & $\begin{array}{c}0,01- \\
0,02\end{array}$ & Damage Control \\
\hline Kotak Elastik & $\begin{array}{l}\text { Fixed } \\
\text { head }\end{array}$ & 250 & 7,5 & 0,115 & 1,54 & $<2,5 \%$ & $\begin{array}{l}\text { Near collapse, } \\
\text { limited safety, } \\
\text { hazard reduced }\end{array}$ \\
\hline Kotak Elastik & $\begin{array}{l}\text { Fixed } \\
\text { head }\end{array}$ & 300 & 7,5 & 0,115 & 1,54 & $\begin{array}{l}0,01- \\
0,02\end{array}$ & Damage Control \\
\hline Kotak Elastik & $\begin{array}{l}\text { Fixed } \\
\text { head }\end{array}$ & 300 & 7,5 & 0,115 & 1,54 & $<2,5 \%$ & $\begin{array}{l}\text { Near collapse, } \\
\text { limited safety, } \\
\text { hazard reduced }\end{array}$ \\
\hline Kotak Elastik & $\begin{array}{l}\text { Fixed } \\
\text { head }\end{array}$ & 350 & 7,5 & 0,11 & 1,47 & $\begin{array}{c}0,01- \\
0,02\end{array}$ & Damage Control \\
\hline Kotak Elastik & $\begin{array}{l}\text { Fixed } \\
\text { head }\end{array}$ & 350 & 7,5 & 0,11 & 1,47 & $<1,5 \%$ & $\begin{array}{c}\text { Life safe-damage } \\
\text { state }\end{array}$ \\
\hline Kotak Elastik & $\begin{array}{l}\text { Fixed } \\
\text { head }\end{array}$ & 400 & 7,5 & 0,11 & 1,47 & $\begin{array}{l}0,01- \\
0,02\end{array}$ & Damage Control \\
\hline Kotak Elastik & $\begin{array}{l}\text { Fixed } \\
\text { head }\end{array}$ & 400 & 7,5 & 0,11 & 1,47 & $<1,5 \%$ & $\begin{array}{c}\text { Life safe-damage } \\
\text { state }\end{array}$ \\
\hline Kotak Elastik & $\begin{array}{l}\text { Fixed } \\
\text { head }\end{array}$ & 500 & 7,5 & 0,108 & 1,44 & $\begin{array}{c}0,01- \\
0,02\end{array}$ & Damage Control \\
\hline Kotak Elastik & $\begin{array}{l}\text { Fixed } \\
\text { head }\end{array}$ & 500 & 7,5 & 0,108 & 1,44 & $<1,5 \%$ & $\begin{array}{c}\text { Life safe-damage } \\
\text { state }\end{array}$ \\
\hline
\end{tabular}


Tabel 2.Hasil analisis tiang spun elastik

\begin{tabular}{|c|c|c|c|c|c|c|c|}
\hline Tipe & & $\begin{array}{l}\text { Diameter } \\
(\mathrm{mm})\end{array}$ & $\begin{array}{l}\text { Depth } \\
(\mathrm{m})\end{array}$ & $\begin{array}{c}\text { Performance } \\
\text { Point }\end{array}$ & $\begin{array}{c}\text { Pile Drift } \\
\text { Ratio } \\
(\%)\end{array}$ & Kategori & Kesimpulan \\
\hline Spun Elastik & $\begin{array}{l}\text { Free } \\
\text { head }\end{array}$ & 300 & 7,5 & 0,04 & 0,54 & 0,01 & $\begin{array}{l}\text { Immediate } \\
\text { Occupancy }\end{array}$ \\
\hline Spun Elastik & $\begin{array}{l}\text { Free } \\
\text { head }\end{array}$ & 300 & 7,5 & 0,04 & 0,54 & $<1,5 \%$ & $\begin{array}{c}\text { Life safe-damage } \\
\text { state }\end{array}$ \\
\hline Spun Elastik & $\begin{array}{l}\text { Free } \\
\text { head }\end{array}$ & 400 & 7,5 & 0,04 & 0,54 & 0,01 & $\begin{array}{l}\text { Immediate } \\
\text { Occupancy }\end{array}$ \\
\hline Spun Elastik & $\begin{array}{l}\text { Free } \\
\text { head }\end{array}$ & 400 & 7,5 & 0,04 & 0,54 & $<1,5 \%$ & $\begin{array}{c}\text { Life safe-damage } \\
\text { state }\end{array}$ \\
\hline Spun Elastik & $\begin{array}{l}\text { Free } \\
\text { head }\end{array}$ & 500 & 7,5 & 0,045 & 0,6 & 0,01 & $\begin{array}{l}\text { Immediate } \\
\text { Occupancy }\end{array}$ \\
\hline Spun Elastik & $\begin{array}{l}\text { Free } \\
\text { head }\end{array}$ & 500 & 7,5 & 0,045 & 0,6 & $<1,5 \%$ & $\begin{array}{c}\text { Life safe-damage } \\
\text { state }\end{array}$ \\
\hline Spun Elastik & $\begin{array}{l}\text { Free } \\
\text { head }\end{array}$ & 800 & 7,5 & 0,06 & 0,8 & 0,01 & $\begin{array}{l}\text { Immediate } \\
\text { Occupancy }\end{array}$ \\
\hline Spun Elastik & $\begin{array}{l}\text { Free } \\
\text { head }\end{array}$ & 800 & 7,5 & 0,06 & 0,8 & $<1,5 \%$ & $\begin{array}{c}\text { Life safe-damage } \\
\text { state }\end{array}$ \\
\hline Spun Elastik & $\begin{array}{l}\text { Free } \\
\text { head }\end{array}$ & 1000 & 7,5 & 0,075 & 1 & $\begin{array}{c}0,01- \\
0,02\end{array}$ & Damage Control \\
\hline Spun Elastik & $\begin{array}{l}\text { Free } \\
\text { head }\end{array}$ & 1000 & 7,5 & 0,075 & 1 & $<1,5 \%$ & $\begin{array}{c}\text { Life safe-damage } \\
\text { state }\end{array}$ \\
\hline Spun Elastik & $\begin{array}{l}\text { Fixed } \\
\text { head }\end{array}$ & 300 & 7,5 & 0,11 & 1,47 & $\begin{array}{c}0,01- \\
0,02\end{array}$ & Damage Control \\
\hline Spun Elastik & $\begin{array}{l}\text { Fixed } \\
\text { head }\end{array}$ & 300 & 7,5 & 0,11 & 1,47 & $<1,5 \%$ & $\begin{array}{c}\text { Life safe-damage } \\
\text { state }\end{array}$ \\
\hline Spun Elastik & $\begin{array}{l}\text { Fixed } \\
\text { head }\end{array}$ & 400 & 7,5 & 0,11 & 1,47 & $\begin{array}{c}0,01- \\
0,02\end{array}$ & Damage Control \\
\hline Spun Elastik & $\begin{array}{l}\text { Fixed } \\
\text { head }\end{array}$ & 400 & 7,5 & 0,11 & 1,47 & $<1,5 \%$ & $\begin{array}{c}\text { Life safe-damage } \\
\text { state }\end{array}$ \\
\hline Spun Elastik & $\begin{array}{l}\text { Fixed } \\
\text { head }\end{array}$ & 500 & 7,5 & 0,11 & 1,47 & $\begin{array}{c}0,01- \\
0,02\end{array}$ & Damage Control \\
\hline Spun Elastik & $\begin{array}{l}\text { Fixed } \\
\text { head }\end{array}$ & 500 & 7,5 & 0,11 & 1,47 & $<1,5 \%$ & $\begin{array}{c}\text { Life safe-damage } \\
\text { state }\end{array}$ \\
\hline Spun Elastik & $\begin{array}{l}\text { Fixed } \\
\text { head }\end{array}$ & 800 & 7,5 & 0,112 & 1,5 & $\begin{array}{c}0,01- \\
0,02\end{array}$ & Damage Control \\
\hline Spun Elastik & $\begin{array}{l}\text { Fixed } \\
\text { head }\end{array}$ & 800 & 7,5 & 0,112 & 1,5 & $<2,5 \%$ & $\begin{array}{l}\text { Near collapse, } \\
\text { limited safety, } \\
\text { hazard reduced }\end{array}$ \\
\hline Spun Elastik & $\begin{array}{l}\text { Fixed } \\
\text { head }\end{array}$ & 1000 & 7,5 & 0,115 & 1,54 & $\begin{array}{c}0,01- \\
0,02\end{array}$ & Damage Control \\
\hline Spun Elastik & $\begin{array}{l}\text { Fixed } \\
\text { head }\end{array}$ & 1000 & 7,5 & 0,115 & 1,54 & $<2,5 \%$ & $\begin{array}{l}\text { Near collapse, } \\
\text { limited safety, } \\
\text { hazard reduced }\end{array}$ \\
\hline
\end{tabular}


Tabel 3. Hasil analisis tiang kelompok arah $\mathrm{x}$

\begin{tabular}{|c|c|c|c|c|c|c|}
\hline Tipe & Jumlah & $\begin{array}{l}\text { Depth } \\
\text { (m) }\end{array}$ & $\begin{array}{c}\text { Performance } \\
\text { Point }\end{array}$ & $\begin{array}{l}\text { Pile Drift } \\
\text { Ratio }(\%)\end{array}$ & Kategori & Kesimpulan \\
\hline $\begin{array}{c}\text { Semi Fixed } \\
\text { Head }\end{array}$ & 7 & 7,5 & 0,085 & 1,14 & $0,01-0,02$ & Damage Control \\
\hline $\begin{array}{c}\text { Semi Fixed } \\
\text { Head }\end{array}$ & 7 & 7,5 & 0,085 & 1,14 & $<1,5 \%$ & $\begin{array}{c}\text { Life safe-damage } \\
\text { state }\end{array}$ \\
\hline $\begin{array}{c}\text { Semi Fixed } \\
\text { Head }\end{array}$ & 8 & 7,5 & 0,096 & 1,28 & $0,01-0,02$ & Damage Control \\
\hline $\begin{array}{c}\text { Semi Fixed } \\
\text { Head }\end{array}$ & 8 & 7,5 & 0,096 & 1,28 & $<1,5 \%$ & $\begin{array}{c}\text { Life safe-damage } \\
\text { state }\end{array}$ \\
\hline $\begin{array}{l}\text { Semi Fixed } \\
\text { Head }\end{array}$ & 10 & 7,5 & 0,12 & 1,6 & $0,01-0,02$ & Damage Control \\
\hline $\begin{array}{c}\text { Semi Fixed } \\
\text { Head }\end{array}$ & 10 & 7,5 & 0,12 & 1,6 & $<2,5 \%$ & $\begin{array}{l}\text { Near collapse, } \\
\text { limited safety, } \\
\text { hazard reduced }\end{array}$ \\
\hline $\begin{array}{c}\text { Semi Fixed } \\
\text { Head }\end{array}$ & 11 & 7,5 & 0,123 & 1,64 & $0,01-0,02$ & Damage Control \\
\hline $\begin{array}{c}\text { Semi Fixed } \\
\text { Head }\end{array}$ & 11 & 7,5 & 0,123 & 1,64 & $<2,5 \%$ & $\begin{array}{l}\text { Near collapse, } \\
\text { limited safety, } \\
\text { hazard reduced }\end{array}$ \\
\hline Fixed head & 7 & 7,5 & 0,07 & 0,94 & 0,01 & $\begin{array}{l}\text { Immediate } \\
\text { Occupancy }\end{array}$ \\
\hline Fixed head & 7 & 7,5 & 0,07 & 0,94 & $<1,5 \%$ & $\begin{array}{c}\text { Life safe-damage } \\
\text { state }\end{array}$ \\
\hline Fixed head & 8 & 7,5 & 0,07 & 0,94 & 0,01 & $\begin{array}{l}\text { Immediate } \\
\text { Occupancy }\end{array}$ \\
\hline Fixed head & 8 & 7,5 & 0,07 & 0,94 & $<1,5 \%$ & $\begin{array}{c}\text { Life safe-damage } \\
\text { state }\end{array}$ \\
\hline Fixed head & 10 & 7,5 & 0,075 & 1 & 0,01 & $\begin{array}{l}\text { Immediate } \\
\text { Occupancy }\end{array}$ \\
\hline Fixed head & 10 & 7,5 & 0,075 & 1 & $<1,5 \%$ & $\begin{array}{c}\text { Life safe-damage } \\
\text { state }\end{array}$ \\
\hline Fixed head & 11 & 7,5 & 0,08 & 1,07 & $0,01-0,02$ & Damage Control \\
\hline Fixed head & 11 & 7,5 & 0,08 & 1,07 & $<1,5 \%$ & $\begin{array}{c}\text { Life safe-damage } \\
\text { state }\end{array}$ \\
\hline
\end{tabular}


Tabel 4. Hasil analisis tiang kelompok arah y

\begin{tabular}{|c|c|c|c|c|c|c|}
\hline Tipe & Jumlah & $\begin{array}{l}\text { Depth } \\
(\mathrm{m})\end{array}$ & $\begin{array}{l}\text { Performance } \\
\quad \text { Point }\end{array}$ & $\begin{array}{l}\text { Pile Drift } \\
\text { Ratio (\%) }\end{array}$ & Kategori & Kesimpulan \\
\hline $\begin{array}{l}\text { Semi Fixed } \\
\text { Head }\end{array}$ & 7 & 7,5 & 0,096 & 1,28 & $\begin{array}{c}0,01- \\
0,02\end{array}$ & Damage Control \\
\hline $\begin{array}{l}\text { Semi Fixed } \\
\quad \text { Head }\end{array}$ & 7 & 7,5 & 0,096 & 1,28 & $<1,5 \%$ & Life safe-damage state \\
\hline $\begin{array}{l}\text { Semi Fixed } \\
\quad \text { Head }\end{array}$ & 8 & 7,5 & 0,11 & 1,47 & $\begin{array}{c}0,01- \\
0,02\end{array}$ & Damage Control \\
\hline $\begin{array}{l}\text { Semi Fixed } \\
\quad \text { Head }\end{array}$ & 8 & 7,5 & 0,11 & 1,47 & $<1,5 \%$ & Life safe-damage state \\
\hline $\begin{array}{l}\text { Semi Fixed } \\
\text { Head }\end{array}$ & 10 & 7,5 & 0,115 & 1,54 & $\begin{array}{c}0,01- \\
0,02\end{array}$ & Damage Control \\
\hline $\begin{array}{l}\text { Semi Fixed } \\
\quad \text { Head }\end{array}$ & 10 & 7,5 & 0,115 & 1,54 & $<2,5 \%$ & $\begin{array}{l}\text { Near collapse, limited } \\
\text { safety, hazard reduced }\end{array}$ \\
\hline $\begin{array}{l}\text { Semi Fixed } \\
\quad \text { Head }\end{array}$ & 11 & 7,5 & 0,123 & 1,64 & $\begin{array}{c}0,01- \\
0,02\end{array}$ & Damage Control \\
\hline $\begin{array}{l}\text { Semi Fixed } \\
\quad \text { Head }\end{array}$ & 11 & 7,5 & 0,123 & 1,64 & $<2,5 \%$ & $\begin{array}{l}\text { Near collapse, limited } \\
\text { safety, hazard reduced }\end{array}$ \\
\hline Fixed head & 7 & 7,5 & 0,07 & 0,94 & 0,01 & Immediate Occupancy \\
\hline Fixed head & 7 & 7,5 & 0,07 & 0,94 & $<1,5 \%$ & Life safe-damage state \\
\hline Fixed head & 8 & 7,5 & 0,079 & 1,06 & $\begin{array}{c}0,01- \\
0,02\end{array}$ & Damage Control \\
\hline Fixed head & 8 & 7,5 & 0,079 & 1,06 & $<1,5 \%$ & Life safe-damage state \\
\hline Fixed head & 10 & 7,5 & 0,079 & 1,06 & $\begin{array}{c}0,01- \\
0,02\end{array}$ & Damage Control \\
\hline Fixed head & 10 & 7,5 & 0,079 & 1,06 & $<1,5 \%$ & Life safe-damage state \\
\hline Fixed head & 11 & 7,5 & 0,085 & 1,14 & $\begin{array}{c}0,01- \\
0,02\end{array}$ & Damage Control \\
\hline Fixed head & 11 & 7,5 & 0,085 & 1,14 & $<1,5 \%$ & Life safe-damage state \\
\hline
\end{tabular}

\section{KESIMPULAN DAN SARAN}

\section{Kesimpulan}

Berdasarkan hasil analisis yang telah dilakukan, dapat disimpulkan bahwa:

1. Pada Tiang Tunggal Kotak Pemodelan Fixedhead, tiang masih berada pada tahap elastis sampai dengan beban $1000 \mathrm{kN}$ dengan displacement $0.1 \mathrm{~m}$. Sedangkan untuk kondisi Pemodelan Freehead, tiang masih berada pada tahap elastis sampai dengan beban $400 \mathrm{kN}$ dengan displacement $0.05 \mathrm{~m}$.

2. Pada Tiang Tunggal Spun Pemodelan Fixedhead, tiang masih berada pada tahap elastis sampai dengan beban $1100 \mathrm{kN}$ dengan displacement 0.1m. Sedangkan untuk kondisi Pemodelan Freehead, tiang masih berada pada tahap elastis sampai dengan beban $500 \mathrm{kN}$ dengan displacement $0.05 \mathrm{~m}$.

3. Bedasarkan Batasan Deformasi ATC 40 dapat disimpulkan bahwa tiang kelompok Semi Fixed Head berada pada kategori Damage Control sedangkan untuk Tiang Kelompok Fixed Head berada pada kategori Immediate Occupancy dan Damage Control 
4. Bedasarkan Batasan Deformasi Pushover Analysis of Underground Structures dapat disimpulkan bahwa tiang kelompok Semi Fixed Head berada pada kategori Life safe-damage state dan Near collapse sedangkan untuk Tiang Kelompok Fixed Head berada pada kategori Life safe-damage state

5. Pada tiang pancang tunggal baik dalam dimensi kotak maupun tiang pancang diameter spun, diperoleh perbandingan dimana nilai pile drift ratio yang dihasilkan pada pemodelan fixedhead lebih besar dari nilai pile drift ratio freehead.

\section{Saran}

1. Perlu dilakukan lebih banyak analisis pada tipe tiang serta ukuran tiang yang berbeda-beda untuk membandingkan hasil pile drift ratio dengan lebih akurat pada desain gempa berbasis gaya lateral dan berbasis perpindahan.

2. Perlu dilakukan analisis tipe tiang dan ukuran tiang pada desain gempa berbasis gaya lateral dan berbasis perpindahan di program lainnya agar dapat mengetahui program mana saja yang memberikan hasil yang paling mendekati.

\section{DAFTAR PUSTAKA}

ATC-40. Seismic Evaluation and Retrofit of Concrete Buildings Volume 1. California: Applied Technology Council. 1996.

Badan Standardisasi Nasional. "Tata Cara Perencanaan Ketahanan Gempa untuk Struktur Bangunan Gedung dan non Gedung (SNI 1726:2012)”. Jakarta: Badan Standarisasi Nasional. 2012.

Badan Standardisasi Nasional. "Tata Cara Perencanaan Ketahanan Gempa untuk Struktur Bangunan Gedung dan non Gedung (SNI 1726:2019)”. Jakarta: Badan Standarisasi Nasional. 2019. 